\title{
Work posture assessment among elderly farmers in Pathumthani Province, Thailand
}

\author{
Teeraphun Kaewdok ${ }^{1}$, Sanpatchaya Sirisawasd ${ }^{2}$, Sasitorn Taptagaporn ${ }^{3 *}$ \\ 1, 2, 3 Faculty of Public Health, Thammasat University, Pathumthani, Thailand
}

\section{Keywords \\ Work \\ Posture \\ Elderly farmer \\ Thiland}

Received: 3 January 2018

Accepted: 8 February 2018

Published: 26 February 2018

\begin{abstract}
Farming is a very large industry in Thailand, and understanding the physically demanding occupation with work tasks that cause Musculoskeletal Disorders (MSDs) and work disability, such as forceful exertions during lifting objects, prolonged static posture, and awkward working postures. This study aims to identify working postures among elderly farmers. Working postures are addressed in the ergonomics research field, and important variables to be taken into account for occupational safety. A cross-sectional study was done on farmer workers aged 60 years and above residing in nine sub-districts, Nong Suea district, Pathum Thani province, Thailand. Data collection was conducted in October 2018. Of the 128 participants, $61 \%$ were women with an average age of $68.50 \pm 4.15$ years. $84.76 \%$ had finished elementary education. The results revealed that average working of $7.32 \pm 2.14$ hours per day and $6.26 \pm 1.51$ days per week. Farmer workers were frequently exposed to injury at work due to an incorrect working posture. The results of this study revealed inappropriate postures when working in farm fields among elderly farmers. This study indicated that older farmers involved activities several awkward postures.
\end{abstract}

(c) 2018 The Author(s). Published by TAF Publishing.

\section{INTRODUCTION}

Farming is a very large industry in Thailand, and understanding the physically demanding occupation with work tasks that cause MSDs [1,2] and work disability, such as forceful exertions during lifting objects, prolonged statics posture, and awkward working postures $[1,3,4,5,6]$. MSDs are impairments of the bodily structures, such as muscles, joints, tendons, ligaments and nerves, which are caused or aggravated primarily by the stress, sickness, a noticeable decrease in overall physical activity levels, the inability to perform certain other physical activities, decreased working efficiency, and a low quality of life $[7,8,9,10]$.

In Thailand, there are approximately 122,859 cases of work-related musculoskeletal disorders in 2017, of theses, 69,094 cases were found in farmer or agriculture workers [11]. Many studies have shown that farming is a strenuous occupation with various health risk with MSDs being some of the most common, especially, elderly farmers who suffer a workplace injury may experience longer recovery periods than their younger counterparts $[12,13]$. The previous 12 months prevalence rate of MSDs among farmers was 56\% [5] and $88.70 \%$ [1] in Thailand, $33.30 \%$ in Korea [4], 69\% in Nepal [14], 88.74\% in China [15], 84.30\% in India [16] and $56 \%$ in Iceland [17].

The number of older persons (defined as aged 60 and over) in Thailand has grown rapidly and will continue to do so in future decades. Future population ageing will occur even more rapidly with the number of older persons projected to increase to over 20 million by 2035, at which point they will constitute over $30 \%$ of the population [18]. Although almost $80 \%$ of older persons received some income from their children, but from literature review found that the proportion of elder person who participate in the workforce about $39.4 \%$. Among persons 60 and older that worked, the majority almost $60 \%$ were engaged in agriculture or the informal sector, a level far higher than among the younger working population, especially, elderly in rural areas [18]. A general consideration is that the employment rate of aging workers ( 55 years and older) must be increased greatly [19]. The changes in physical capacity in relation to aging

${ }^{*}$ corresponding author: Sasitorn Taptagaporn

†email: sasitorn.t@fph.tu.ac.th 
are often difficult to distinguish because, for example, work and living habits can accelerate or slow down such changes [19].

According to Australia Physiotherapy Association [20], older workers tend to have more severe work-related injuries, along with more severe outcomes of injury, such as longer rehabilitation and greater lost work time [21]. During farm work, farmers usually use a variety of different awkward postures while performing various manual tasks for an extended period of time [22]. Postures, especially those involving severe flexion or lateral twisting and bending, have been found to be significantly related to MSDs, especially, low back pain [3, 22]. In previous studies, the working posture assessment was obtained from various groups of farmers that produced in agriculture industry. Thus, the posture assessment in the elderly farmers which a specific or vulnerable group of farmers was less well known. Therefore, the aim of this study is to identify working postures among elderly farmers. This information will provide baseline data to support the improvement of occupational health and safety among elderly farmers.

\section{LITERATURE REVIEW}

\section{A. Working Postures}

Working postures are addressed in the ergonomics research field and important variables to be taken into account for occupational safety [23]. Working posture can be defined as the orientation of body parts in a work area while a worker performing a task. It is considered by the characteristics of the worker, workstation and work process. The element of work system such as dimensions, position, and design of workstation must be suited with the physical of workers so that they can perform the task in safe working posture [24]. Farmer workers were frequently exposed to injury at work due to an incorrect working posture. Improper working posture such as bending, twisting, overreaching, repetitive task and uncomfortable posture contribute to MSDs.

\section{B. Musculoskeletal Disorders Related to Working Pos- ture}

MSDs are impairments of the bodily structures, such as muscles, joints, tendons, ligaments and nerves, which are caused or aggravated primarily by the performance of work and by the effects of the immediate environment in which work is carried out [7]. The risk factors for MSDs include awkward posture, repetition, force, vibration, velocity of work, tool design, and personal factors [3]. Musculoskeletal symptoms include pain, sensitivity, weakness, swelling, and numbness. Inappropriate working postures produce harmful physical exposures that can cause musculoskeletal injury, pain, and kinematic disorders. The overexertion, differential fatigue and cumulative load theories explain the precipitation of musculoskeletal injuries [23]. Studies have shown that inappropriate working posture must be considered in order to categorize the level of physical exertion and musculoskeletal symptoms $[4,5,22,24,25,26]$.

\section{Assessment of Working Posture}

There are various methods available for ergonomic and occupational health practitioners for assessment of exposure related to working posture. Methods can be categorized including pen and paper based observation methods, videotaping and computer-aided analysis, direct or instrumental techniques, and various approaches to self-report assessment [27]. The methods have been developed for assessing exposure to risk factors for MSDs. The choice of methods will depend upon the nature of the investigation and the purposes for which the data will be use in order to differentiate between the tools, consider the following questions $[27,28]$.

1) Task: 1.1. Which area of the body is being assessed, for example, whole body or upper limb?

1.2. Does the activity include static and dynamic postures?

2) Sensitivity and generality: 2.1 How detailed will the assessment be?

2.2 Will the same postural analysis tool be used for a range of tasks in several industrial settings?

Several studies have used postural analysis methods to identify occupational musculoskeletal problems $[22,24,26$, 29].

\section{METHODOLOGY}

A cross-sectional study was done on farmer workers aged 60 years and above residing in nine sub-districts, Nong Suea district, Pathum Thani province, Thailand. Data collection was conducted in October 2018. A convenience sampling method was used to select participants. Informed consent was obtained from all participants taking part in the study which was approved by the Ethics Review SubCommittee for Research Involving Human Research Subjects of Thammasat University, No. 3. Three-part questionnaire included demographic data, working posture checklist and environment, and postural work sheet. Rapid Entire Body Assessment Technique (REBA) was developed to provide a quick and easy observational postural analysis tool 
for whole body activities (static and dynamic) giving a musculoskeletal risk action level [28]. REBA technique was used to assess working posture of work related musculoskeletal risk factors among elderly farmers. These technique provide a quick analysis of the demands on a person's musculoskeletal system when performing a specific task [28].

A video of the workers during an activity was recorded. After recording the video, it was cropped to get snapshots for the analysis of posture of the worker. The snapshots were analyzed to fill the scores REBA work sheets. Selection of the postures to be evaluated should be based on 1) the most difficult postures and work tasks based on worker interview and initial observation, 2) the posture sustained for the longest period of time, or 3) the posture where the highest force loads occur. After interviewing and observing the worker the evaluator can determine if only one arm should be evaluated, or if an assessment is needed for both sides. Postural score increases when posture diverged from the neutral position. The body parts are grouped into: Group A includes trunk, neck, and legs, while group B includes upper and lower arms and wrist. This gives a final REBA SCORE, which is then interpreted into an action level. There are five action levels for risk estimation relate MSDs and give an indication of the urgency of avoiding or reducing the risk of the assessed posture $(0=$ negligible, $1=$ low, $2=$ medium, 3 $=$ high and $4=$ very high) [28]. The frequency and percentage were analyzed and presented.

\section{RESULTS}

Of the 128 participants, $61 \%$ were women with average age of $68.50 \pm 4.15$ years. $84.76 \%$ had finished elementary education. The results revealed that, average working of $7.32 \pm$ 2.14 hours per day and $6.26 \pm 1.51$ days per week. The average work experience was $33.04 \pm 16.99$ years. The majority of working posture were bending trunk, working with the neck bend and twisting upper body with $97.28 \%, 96.84 \%$, and $95.99 \%$, respectively in Table 1 .

TABLE 1

WORKING POSTURES OF THE ELDERLY FARMERS

\begin{tabular}{lcc}
\hline \hline Working Postures & Frequency & Percentage \\
\hline \hline Squatting or kneeling & 98 & 76.86 \\
Exertion manual work & 106 & 82.84 \\
Arm elevation above shoulder & 110 & 85.92 \\
Repetitive work >5 minute & 118 & 92.44 \\
Wrist twist & 122 & 95.56 \\
Twisting trunk & 123 & 95.99 \\
Working with neck bend & 124 & 96.84 \\
Bending trunk forward & 125 & 97.28 \\
\hline \hline
\end{tabular}

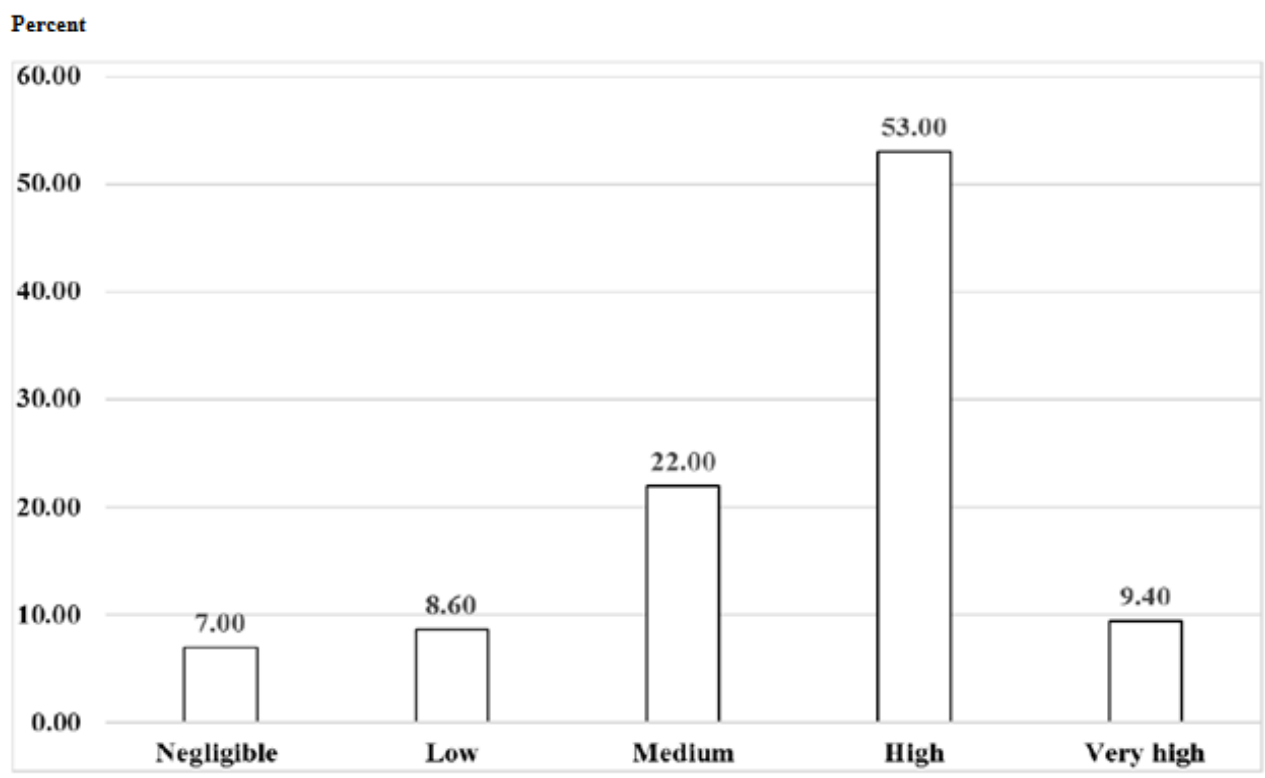

Fig. 1. Percentage of risk level (REBA) of working postures among the elderly farmers 
The final snapshot working posture consisted of 128 pictures mostly in the performing tasks. The postures of elderly farmers operating were completely evaluated using the REBA. No difference was found between the grand REBA score performed by the right and left sides of individual workers. The results of postural risk assessment showed that most of the postures were at the fourth level of the risk with $53.00 \%$, which is the high risk and require to investigate and implement for the changes, followed by the third level with $22.00 \%$, which the medium risk as shown in Figures 1.

\section{DISCUSSION}

Farmer workers were frequently exposed to injury at work due to an incorrect working posture. The results of this study revealed inappropriate postures when working in farm field among elderly farmers. More than $50 \%$ of working postures were found to be at high risk, necessitating further assessments and changes. This result agrees with studies identified earlier that farm workers were at risk of MSDs due to awkward postures [13, 22, 25, 26, 29]. Harmful postures which were found while performing tasks attributed to musculoskeletal injury exposure required corrective measures. Posture influences the strength that muscles are able to generate. In farm workplace, the layout of work stations, tasks, and tools used also influence the amount of physical load that workers are exposed to awkward posture [23]. In addition, several types of MSD have been identified amongst older worker groups varying from simple aches and pains, discomfort and tingling sensations in the different regions of the body to overuse injuries and conditions [30]. [13] found that the risk of MSDs increases significantly with age among Korean farmers. Aging is an especially important occupational health issue, as functional capacity is affected by age-related changes in body composition, such as reduced lean body mass, increased fat mass, and possibly decreased muscle quality. [22] found that agricultural workers of Uttarakhand, India suffered from pain especially in the low back, knees, hands shoulder and neck. The average REBA score observed was 10 .

The current study also showed that several awkward postures were adopted during farm working such as bending or twisting upper body trunk, working with neck bend, squatting, kneeling and arm elevation above shoulder. It can be explained that farm workers have to perform various manual, continuous rigorous tasks in the agricultural field. Static forward-bend postures, often associated with working at or near ground level, are commonly observed in agriculture, construction, mining and certain other industries that have a high incidence of low back pain [3]. Therefore, working in awkward position have been identified as the cause of injuries and considered to be unacceptable postures and leads to the development of musculoskeletal disorder [24].

In addition, from the survey, it was found that the elderly famers working with a prolonged period of time with 7.32 hours per day and 6.26 days per week. [22] found that prolonged work activity, high repetitiveness, and remaining constantly in an awkward posture for a prolonged period of time were the major factors of drudgery, acute pain and discomfort among farm workers. The older workers are more susceptible to work-related MSD than younger workers because of decreased functional capacity [30]. Prolonged work duration of the current study might contribute to unavoidable awkward positions and overexertion among the elderly person. Therefore, proper rest periods were recommended to avoid any MSDs in future. This finding demonstrated the relevant authorities and the elderly farmers must understand the principal of working at the neutral position. Working in awkward position will increase the possibility for body to get injury [24]. The most critical job that leads to poor working posture should be eliminated or reduced to reduce risk of musculoskeletal injury.

There are several limitations should be considered when evaluating our findings. First, the cross-sectional study, reviewed video recording were presented by the most frequent or worst postures. However, these working postures could still be the representative of most common uses. Second, the study could not identify a causal association with MSDs at work among older farmers. Third, the study was not compared the posture risk level with the risk in the general population. Therefore, future comparison of older farmers with the general population may strengthen our understanding of MSDs. Further investigation as well as the implementation of ergonomic interventions are required for elderly person to prevent musculoskeletal injuries during work in agricultural sector.

\section{CONCLUSION}

This study indicated that older farmers involved activities several awkward postures. The majority of working posture were bending trunk, working with the neck bend and twisting upper body. REBA posture analysis identified that most of the postures were at the fourth level of the risk, which is the high risk and require to investigate and implement for the changes. It is necessary to control not to use awkward postures in farm tasks to prevent musculoskeletal injuries. The findings from the current study would be 
useful for promoting safety and need of implementation of ergonomics interventions with proper awareness among elderly farmers.

\section{ACKNOWLEDGMENT}

The authors gratefully acknowledge the financial support provided by Institute for Continuing Education and Human Resources, Thammasat University.

\section{REFERENCES}

[1] Phajan T, Nilvarangkul K, Settheetham D, Laohasiriwong W. Work-related musculoskeletal disorders among sugarcane farmers in north-eastern Thailand. Asia Pacific Journal of Public Health. 2014;26(3):320-327. doi: https://doi.org/10. $1177 / 1010539514528026$.

[2] Zali SH, Tahmasb R. Medicinal plants of Farashband tribe's winter pastures and their traditional uses. Journal of Advances in Health and Medical Sciences. 2016;2(1):18-27. doi: https://doi.org/10.20474/jahms-2.1.3.

[3] Fathallah F, Meyers J, Chapman L, Karsh B, Marras W, Karwowski W. Ergonomic industrial interventions: Agriculture. Taylor and Francis CRC Press; 2006.

[4] Park JH, Lim HS, Lee K. Work-related musculoskeletal symptoms among dairy farmers in Gyeonggi Province, Korea. Journal of Preventive Medicine and Public Health. 2010;43(3):205-212. doi: https://doi.org/10.3961/jpmph.2010.43. 3.205.

[5] Taechasubamorn P, Nopkesorn T, Pannarunothai S. Prevalence of low back pain among rice farmers in a rural community in Thailand. Journal of the Medical Association of Thailand. 2011;94(5):616-630.

[6] Juliansyah E, Asnol UB. Workers behavior in maintaining health management waste in the final disposal. International Journal of Health and Medical Sciences. 2016;2(2):32-36,. doi: https://doi.org/10.20469/ijhms.2.30002-2.

[7] European Agency for Safety and Health at Work (OSHA). Safety and health at work European good practice awards: Prevention of work-related MSDs in practice; 2007. Available from: https://bit.ly/2Lgjv4D.

[8] McGorry RW, Bspt BSW, Snook SH, Hsiang SM. The relation between pain intensity, disability, and the episodic nature of chronic and recurrent low back pain. Spine. 2000;25(7):834-841. doi: https://doi.org/10.1097/ 00007632-200004010-00012.

[9] Ceran F, Ozcan A. The relationship of the functional rating index with disability, pain, and quality of life in patients with low back pain. Medical Science Monitor. 2006;12(10):435-439.

[10] Mendez AJP. Factors influencing stress and mental health: A comprehensive review of the literature. International Journal of Health and Medical Sciences. 2015;1(2):42-47. doi: https://doi.org/10.20469/ijhms.30004-2.

[11] Statistical Office. Number of patients work related musculoskeletal disorders; n.d. Available from: https://bit.ly/ 2RWCm7g.

[12] Rogers E, Wiatrowksi WJ. Injuries, illnesses, and fatalities among older workers. Monthly Lab Review. 2005;128:24-30.

[13] Kang MY, Lee MJ, Chung H, Shin DH, Youn KW, Im SH, et al. Musculoskeletal disorders and agricultural risk factors among Korean farmers. Journal of Agromedicine. 2016;21(4):353-363. doi: https://doi.org/10.1080/1059924x.2016. 1178612.

[14] Bhattarai D, Singh S, Baral D, Sah R, Budhathoki S, PK P. Work-related injuries among farmers: A cross-sectional study from rural Nepal. Journal of Occupational Medicine and Toxicology. 2016;11(1):48-50. doi: https://doi.org/10.1186/ s12995-016-0137-2.

[15] Jia N, Li T, Hu S, Zhu X, Sun K, Yi L, et al. Prevalence and its risk factors for low back pain among operation and maintenance personnel in wind farms. BMC Musculoskeletal Disorders. 2016;17(1):314-320. doi: https://doi.org/10.1186/ s12891-016-1180-y.

[16] Hemalatha K, Bharanidharan G, Anusha T. Prevalence of musculoskeletal disorder among agricultural workers in rural area of Tamil Nadu: A cross sectional study. International Journal of Community Health and Medical Research. 2017;3(3):26-31.

[17] Osborne A, Blake C, McNamara J, Meredith D, Phelan J, Cunningham C. Musculoskeletal disorders among Irish farmers. Occupational Medicine. 2010;60(8):598-603. doi: https://doi.org/10.1093/occmed/kqq146.

[18] Foundation of Thai Gerontology Research and Development Institute (TGRI). Situation of the Thai Elderly; 2016. Available from: https://bit.ly/2BT98Rr. 
[19] Vogel K, Eklund J. On physiological demands and sustainability in meat cutting. Ergonomics. 2015;58(3):463-479. doi: https://doi.org/10.1136/oem.58.8.546.

[20] Association AP. Ageing Australia Workforce;. Available from: https://bit.ly/2UFtSDd.

[21] Silverstein M. Meeting the challenges of an aging workforce. American Journal of Industrial Medicine. 2008;51(4):269-280. doi: https://doi.org/10.1002/ajim.20569.

[22] Ojha P, Kwatra S. An ergonomic study on the assessment of work related musculoskeletal disorder risks among agriculture workers of Uttarakhand, India. International Journal of Scientific \& Engineering Research. 2014;5(1):188-191.

[23] Vieira E, Kumar S. Working postures: A literature review. Journal of Occupational Rehabilitation. 2004;14(2):143-159.

[24] Zein R, Halim I, Azis N, Saptari A, SR K. A survey on working postures among Malaysian industrial workers. Procedia Manufacturing. 2015;2(1):450-459. doi: https://doi.org/10.1016/j.promfg.2015.07.078.

[25] Gangopadhyay S, Ghosh T, Das T, Ghoshal G, Das B. Effect of working posture on occurrence of musculoskeletal disorders among the sand core making workers of West Bengal. Central European Journal of Public Health. 2010;18(1):38-42.

[26] Mishra aS D. Musculoskeletal and risk assessment during threshing of rice-grains. In: 3rd International Conference on Design, Analysis, Manufacturing and Simulation, Chennai, India; 2018. .

[27] David G. Ergonomic methods for assessing exposure to risk factors for work-related musculoskeletal disorders. Occupational Medicine. 2005;55(3):190-199. doi: https://doi.org/10.1093/occmed/kqi082.

[28] Hignett S, McAtamney L. Rapid Entire Body Assessment (REBA). Applied Ergonomics. 2000;31(2):201-205. doi: http://dx.doi.org/10.1016/S0003-6870(99)00039-3.

[29] Kuta l, Ciez J, Miotek M. Musculoskeletal load assessment of farmers during selected agricultural works. Procedia Manufacturing. 2015;3(1):1696-1703. doi: https://doi.org/10.1016/j.promfg.2015.07.990.

[30] Health and Safety Executive. Ageing and work-related musculoskeletal disorders: A review of the recent literature; 2010. Available from: https://bit.ly/2QNtCmQ. 